\title{
Erratum to: A New Meta-heuristic Algorithm for Maximizing Lifetime of Wireless Sensor Networks
}

\author{
Habib Mostafaei ${ }^{1} \cdot$ Mohammad Shojafar $^{2}$
}

Published online: 18 March 2015

(C) Springer Science+Business Media New York 2015

\section{Erratum to: Wireless Pers Commun DOI 10.1007/s11277-014-2249-2}

The Acknowledgements section in the original publication was incomplete. Please find the complete section printed below. The authors of the paper apologize for any inconvenience that may result from this oversight.

Acknowledgments The authors would like to thank Dr. Jamshid Bagherzadeh from Urmia University for his assistance. We thank our anonymous referees for their helpful comments. This work has been supported by the project number 41232 at Islamic Azad University, Urmia branch, Iran.

The online version of the original article can be found under doi:10.1007/s11277-014-2249-2.

Habib Mostafaei

h.mostafaei@iaurmia.ac.ir

Mohammad Shojafar

shojafar@diet.uniroma1.it

1 Department of Computer Engineering, Urmia Branch, Islamic Azad University, Urmia, Iran

2 Department of Information Engineering, Electronics (DIET), Sapienza University of Rome, Rome, Italy 